Maxam, A. M., \& Gilbert, W. (1980) Methods Enzymol. 65, 499-560.

Morgan, E. A. (1986) J. Bacteriol. 168, 1-5.

Morgan, E. A., Gregory, S. T., Sigmund, C. D., \& Borden, A. (1987) in Genetics of Translation, New Approaches (Tuite, M., Picard, M., \& Bolotin-Fukuhara, M., Eds.) NATO ASI Series, pp 43-53, Springer-Verlag, New York. Morgan, W. D., Bear, D. G., \& von Hippel, P. H. (1983) J. Biol. Chem. 258, 9553-9574.

Mott, J. E., Grant, R. A., Ho, Y.-S. \& Platt, T. (1985) Proc. Natl. Acad. Sci. U.S.A. 82, 88-92.

Nakamura, Y., \& Uchida, H. (1983) MGG, Mol. Gen. Genet. 190, 196-203.

Olins, P. D., Erickson, B. D., \& Burgess, R. R. (1983) Gene $26,11-18$.

Platt, T. (1986) Annu. Rev. Biochem. 55, 339-372.

Postle, K., \& Good, R. (1985) Cell (Cambridge, Mass.) 41, 577-585.
Schmidt, M. C., \& Chamberlin, M. J. (1984a) Biochemistry 23, 197-203.

Schmidt, M. C., \& Chamberlin, M. J. (1984b) J. Biol. Chem. 259, 15000-15002.

Sigmund, C. D. (1987) Ph.D. Dissertation, State University of New York at Buffalo.

Sigmund, C. D., \& Morgan, E. A. (1988) Biochemistry (preceding paper in this issue).

Stewart, V., \& Yanofsky, C. (1985) J. Bacteriol. 164, 731-740.

Tsugawa, A., Kurihara, T., Zuber, M., Court, D. L., \& Nakamura, Y. (1985) EMBO J. 4, 2337-2342.

Viera, J., \& Messing, J. (1982) Gene 19, 259-268.

Wu, A. M., Christie, G. E., \& Platt, T. (1981) Proc. Natl. Acad. Sci. U.S.A. 78, 2913-2917.

Young, R. A. (1979) J. Biol. Chem. 254, 12725-12731.

Young, R. A., \& Steitz, J. A. (1979) Cell (Cambridge, Mass.) $17,225--234$.

\title{
Structural Changes of Nucleosomal Particles and Isolated Core-Histone Octamers Induced by Chemical Modification of Lysine Residues ${ }^{\dagger}$
}

\author{
Maria Angela Nieto and Enrique Palaciăn* \\ Centro de Biologia Molecular, Consejo Superior de Investigaciones Cientificas y Universidad Autōnoma de Madrid, \\ Cantoblanco, 28049 Madrid, Spain
}

Received July 27, 1987; Revised Manuscript Received January 22, 1988

\begin{abstract}
Treatment of nucleosomal particles and isolated core-histone octamers with dimethylmaleic anhydride, but not with acetic anhydride, is accompanied by a biphasic release of the two H2A.H2B dimers, the first dimer being more easily released than the second. With both kinds of particles, $50 \%$ of histones $\mathrm{H} 2 \mathrm{~A}$ and $\mathrm{H} 2 \mathrm{~B}$ are released for modification of approximately $35 \%$ of the histone amino groups. The similar behavior of nucleosomal particles and isolated core-histone octamers is consistent with the same structure of the histone octamer in the nucleosomal particle and in the free octamer in $2 \mathrm{M} \mathrm{NaCl}$. The described release of $\mathrm{H} 2 \mathrm{~A} \cdot \mathrm{H} 2 \mathrm{~B}$ dimers allows the preparation of nucleosomal particles deficient in one $\mathrm{H} 2 \mathrm{~A} \cdot \mathrm{H} 2 \mathrm{~B}$ dimer and of the histone hexamers $\mathrm{H} 2 \mathrm{~A} \cdot \mathrm{H} 2 \mathrm{~B} \cdot(\mathrm{H} 3 \cdot \mathrm{H} 4)_{2}$. For more extensive modifications, both reagents, acetic and dimethylmaleic anhydrides, cause the dissociation of nucleosomal particles with liberation of doublestranded DNA, which suggests that lysine amino groups are involved in the binding of histones to DNA. The modified nucleosomal particles are more sensitive to ionic strength than those untreated, and the presence of salt $(\mathrm{NaCl})$ increases the extent of DNA release. The histones corresponding to the liberated DNA, except $\mathrm{H} 2 \mathrm{~A}$ and $\mathrm{H} 2 \mathrm{~B}$ released with dimethylmaleic anhydride, are apparently bound to the DNA-containing particles as extra histones.
\end{abstract}

$T_{\text {h }}$ histone octamer to form nucleosomal particles appear to be essentially electrostatic. Changes in these electrostatic interactions, as those produced by the physiological acetylation of lysine residues, might cause structural alterations of functional significance (Weisbrod, 1982; Reeves, 1984). The electrostatic forces within the nucleosomal particle are weakened by increasing the ionic strength and by modification of the interacting charged groups. Acylation of lysine residues has been used to change the interaction of histones with DNA. The chemical acetylation of chromatin decreases the salt

${ }^{\dagger}$ This work was supported in part by the Comision Asesora de Investigaciôn Cientifica y Técnica (Grant 0214-84002) and the Fondo de Investigaciones Sanitarias de la Seguridad Social (Spain). concentration needed to release core histones (Wong \& Marushige, 1976). Treatment of nucleosomal particles with dimethylmaleic anhydride causes rearrangement of the nucleosomal components, with release of histones $\mathrm{H} 2 \mathrm{~A}$ and $\mathrm{H} 2 \mathrm{~B}$ and of single-stranded DNA, and formation of residual particles deficient in histones $\mathrm{H} 2 \mathrm{~A}$ and $\mathrm{H} 2 \mathrm{~B}$ but containing an excess of $\mathrm{H} 3$ and $\mathrm{H} 4$ (Jordano et al., 1984a,c). Structural studies of the residual particles are consistent with the stabilization by histones $\mathrm{H} 2 \mathrm{~A}$ and $\mathrm{H} 2 \mathrm{~B}$ of a DNA length of 50-70 base pairs per nucleosome (Jordano et al., 1984b). Regeneration of the modified amino groups of the residual particles plus the complementary fraction containing histones $\mathrm{H} 2 \mathrm{~A}$ and $\mathrm{H} 2 \mathrm{~B}$ is accompanied by reconstitution of nucleosomal particles with the structural properties of the original nucleosomes (Jordano et al., 1984a,b). Recently, we have 
found that the release of single-stranded DNA during modification is caused by the local and transient changes in $\mathrm{pH}$ induced by the base added to prevent the fall in $\mathrm{pH}$ (Nieto \& Palaciann, 1987). When modification takes place in the absence of base addition, no release of single-stranded DNA is observed.

The present work describes the structural changes of nucleosomal particles and core-histone octamers produced by modification of lysine residues with acetic and dimethylmaleic anhydrides, in the absence of base addition, as well as the effects of moderate salt concentrations on the modified nucleosomal particles.

\section{Materials and Methods}

Preparation of Nucleosomal Particles and Histone Octamers. Nuclei were obtained from chicken erythrocytes after lysis of the cells in a buffer solution containing Nonidet P40 (Weintraub et al., 1975). The isolated nuclei were digested with micrococcal nuclease (Cooper) and extracted with 0.25 $\mathrm{mM}$ ethylenediaminetetraacetic acid (EDTA) (pH 8.0) (Lacy \& Axel, 1975). Nucleosomal particles containing histones $\mathrm{H} 1$ and $\mathrm{H} 5$ were precipitated from the extract with $100 \mathrm{mM} \mathrm{KCl}$, resuspended in $10 \mathrm{mM}$ Tris- $\mathrm{HCl}(\mathrm{pH} \mathrm{8.2)}$ containing $5 \mathrm{mM}$ EDTA, and dialyzed overnight at $4^{\circ} \mathrm{C}$ against the same buffer solution. From the dialyzed preparation, a mononucleosomal fraction was isolated by centrifugation in 5-20\% sucrose gradients containing the resuspension buffer components. To dissociate histones $\mathrm{H1}$ and $\mathrm{H} 5$, the mononucleosomal preparation was dialyzed against $10 \mathrm{mM}$ Tris- $\mathrm{HCl}(\mathrm{pH} \mathrm{8.2)}, 0.7$ $\mathrm{M} \mathrm{NaCl}$, and $5 \mathrm{mM}$ EDTA. The nucleosomal particles were separated from the released histones by sucrose gradient centrifugation in the presence of $0.7 \mathrm{M} \mathrm{NaCl}$. DNA from nucleosomal particles had an average length of 160 base pairs, as determined by polyacrylamide gel electrophoresis, with the digestion products of plasmid pBR322 treated with nuclease HaelII used as length markers. Core-histone octamers were prepared from nuclei by salt extraction (4 M NaCl) after removal of histones $\mathrm{H} 1$ and $\mathrm{H} 5(0.7 \mathrm{M} \mathrm{NaCl})$, as described by Ruiz-Carrillo and Jorcano (1979), except that for the extraction $4 \mathrm{M} \mathrm{NaCl}$ was used instead of $2 \mathrm{M} \mathrm{NaCl}$.

Chemical Modification of Nucleosomal Particles and Histone Octamers. Nucleosomal particles $(0.1 \mathrm{mg}$ of DNA $/ \mathrm{mL}$ ) and histone octamers (5 mg/mL), in $200 \mathrm{mM}$ $N$-[tris(hydroxymethyl)methyl]glycine (Tricine) (pH 8.2) and variable $\mathrm{NaCl}$ concentration ( $2 \mathrm{M}$ for histone octamers), were treated at room temperature with different amounts of acetic anhydride (AA) or dimethylmaleic anhydride (DMMA) (dissolved in dioxane, $50-200 \mathrm{mg}$ of anhydride $/ \mathrm{mL}$ ). Reaction took place in the absence of base addition. The modified preparations were dialyzed at $4^{\circ} \mathrm{C}$ against $10 \mathrm{mM}$ Tris- $\mathrm{HCl}$ ( $\mathrm{pH}$ 8.2), $5 \mathrm{mM}$ EDTA, and variable $\mathrm{NaCl}$ concentration (2 $\mathrm{M}$ for histone octamers).

Determination of the Modification Degree. The extent of modification of protein amino groups was determined in two different ways: by measuring the radioactivity incorporated into the macromolecules from ${ }^{14} \mathrm{C}$-labeled $\mathrm{AA}$ or by evaluating the extent of reaction with trinitrobenzenesulfonic acid of the modified preparations. The radioactivity incorporation procedure is suitable for determining the degree of modification of protein amino groups in nucleosomal particles, because the modifications by carboxylic acid anhydrides of the DNA moiety and that of other protein reactive groups are negligible (Bernad et al., 1986). With this procedure, the extent of modification produced by DMMA was evaluated from the radioactivity incorporated in the DMMA-modified preparation when treated with ${ }^{14} \mathrm{C}$-labeled $\mathrm{AA}$, under conditions that cause

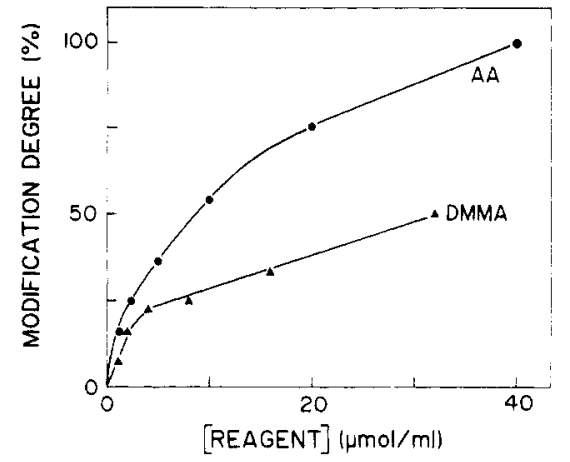

FIGURE 1: Degree of modification of nucleosomal particles treated with different amounts of AA and DMMA. Nucleosomal particles were treated, in the absence of $\mathrm{NaCl}$, with the indicated amounts of AA or DMMA. The modification degree was determined by measuring radioactivity incorporated, as described under Materials and Methods.

complete modification of histone free amino groups (treatment with $2 \mathrm{mg}$ of $\mathrm{AA} / \mathrm{mL}$, with addition of $1 \mathrm{M} \mathrm{NaOH}$ to avoid the fall in $\mathrm{pH}$, not shown).

Analytical Procedures. Preparations were centrifuged in linear 5-20\% sucrose gradients containing $10 \mathrm{mM}$ Tris- $\mathrm{HCl}$ (pH 8.2), $5 \mathrm{mM}$ EDTA, $0.1 \mathrm{mM}$ phenylmethanesulfonyl fluoride, and the indicated $\mathrm{NaCl}$ concentration. Centrifugation took place in a Beckman SW40 rotor at $30000 \mathrm{rpm}$ and $6^{\circ} \mathrm{C}$ for $26 \mathrm{~h}$, for nucleosomal particles, and in a SW65 rotor at $60000 \mathrm{rpm}$ and $4^{\circ} \mathrm{C}$ for $40 \mathrm{~h}$, for histone octamers. The distribution along the gradient of materials absorbing at 254 $\mathrm{nm}$ (nucleosomal particles and DNA) or at $280 \mathrm{~nm}$ (histones) was determined with an ISCO density fractionator, which was also used for the separation of fractions. Electrophoretic analysis of histones was conducted in polyacrylamide gels, $15 \%$ polyacrylamide or a linear gradient from 10 to $20 \%$ (Figure 2 ), containing $0.1 \%$ sodium dodecyl sulfate (Laemmli, 1970). Histone concentration was determined according to Bradford (1976) or to Lowry et al. (1951). The extent of DNA dissociated from nucleosomal particles was estimated from the areas corresponding to free DNA and to nucleosomal particles in the sedimentation patterns. The double-stranded nature of DNA was verified by elution from hydroxyapatite columns as previously described (Nieto \& Palaciân, 1987). Electrophoresis of nucleosomal particles under nondenaturing conditions was conducted in $5 \%$ polyacrylamide gels, using as electrophoresis buffer $89 \mathrm{mM}$ Tris-borate, $89 \mathrm{mM}$ boric acid, and $2 \mathrm{mM}$ EDTA.

\section{RESULTS}

Figure 1 shows the degree of modification of the amino groups of histones in nucleosomal particles treated with different amounts of AA or DMMA. The extent of modification obtained with AA is much higher than that corresponding to DMMA for equivalent amounts of reagent. Modification is accompanied by a decrease in the sedimentation rate of the particles, in agreement with previous work (Jordano et al., 1984a). For the same degree of modification, DMMA causes a larger change in sedimentation rate than AA (not shown). This result is probably due to the larger expansion of the nucleosomal particles induced by the introduction of negative charges by DMMA and also to the release of histones $\mathrm{H} 2 \mathrm{~A}$ and $\mathrm{H} 2 \mathrm{~B}$ by this reagent (see below).

Biphasic Release of $\mathrm{H} 2 \mathrm{~A} \cdot \mathrm{H} 2 \mathrm{~B}$ Dimers from Nucleosomal Particles and from the Isolated Core-Histone Octamers by Modification with DMMA. Modification of nucleosomal particles with DMMA causes the release of histones $\mathrm{H} 2 \mathrm{~A}$ and H2B. Figure 2 shows the sedimentation patterns of prepa- 


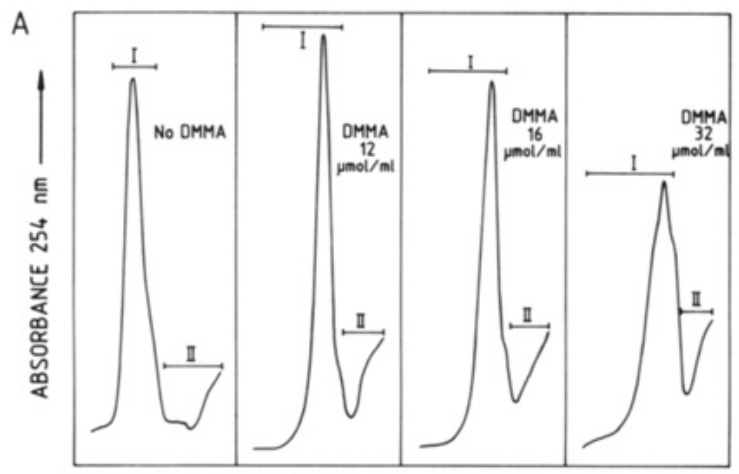

B

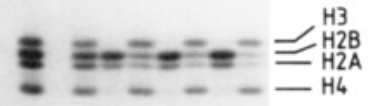

FRACTION $\frac{\text { II I I II I II I II I II I }}{\underbrace{}_{12}} \frac{\underbrace{}_{16}}{32}$

$\mu \mathrm{mol} / \mathrm{ml}$

FIGURE 2: Release from nucleosomal particles of histones $\mathrm{H} 2 \mathrm{~A}$ and H2B by modification with DMMA. Nucleosomal particles were treated, in the absence of $\mathrm{NaCl}$, with the indicated amounts of DMMA. (A) Sedimentation patterns. The bars (I and II) indicate the fractions isolated for histone electrophoresis and determination of the extent of histone release (Figure 4). (B) Electrophoresis of the histones present in the residual particles (fractions I) and of those released by the treatments (fractions II). The amounts of fractions I and II used for electrophoresis were not complementary.

rations modified with different amounts of reagent and the electrophoresis of the histones present in the DNA-containing particles (fractions I) and in the gradient region close to the meniscus (fractions II). The released fractions contain histones $\mathrm{H} 2 \mathrm{~A}$ and $\mathrm{H} 2 \mathrm{~B}$, while the residual particles retain the whole complement of histones $\mathrm{H} 3$ and $\mathrm{H} 4$ but are increasingly deficient in $\mathrm{H} 2 \mathrm{~A}$ and $\mathrm{H} 2 \mathrm{~B}$. The shoulder in the sedimentation pattern of the preparations treated with 16 and $32 \mu \mathrm{mol}$ of DMMA/mL (Figure 2A) corresponds to free DNA.

Since the octamer of core histones can be obtained in $2 \mathrm{M}$ $\mathrm{NaCl}$, we wanted to know whether the modification of this particle with DMMA is also accompanied by release of histones H2A and H2B. Sedimentation analysis in sucrose gradients of preparations of histone octamers modified with different amounts of reagent (Figure 3A) shows the formation of a component (II) with a sedimentation coefficient lower than that of the octamer and corresponding to $\mathrm{H} 2 \mathrm{~A} \cdot \mathrm{H} 2 \mathrm{~B}$ dimers. In addition, the sedimentation coefficient of the fastest component (I), initially the intact unmodified octamer, decreases with increasing levels of modification. The slower component contains equimolecular amounts of histones $\mathrm{H} 2 \mathrm{~A}$ and $\mathrm{H} 2 \mathrm{~B}$, while the faster component includes all histones $\mathrm{H} 3$ and $\mathrm{H} 4$ present and decreasing amounts of $\mathrm{H} 2 \mathrm{~A}$ and $\mathrm{H} 2 \mathrm{~B}$.

The release of histones $\mathrm{H} 2 \mathrm{~A}$ and $\mathrm{H} 2 \mathrm{~B}$ from nucleosomal particles and histone octamers is very similar, in spite of the very different conditions used for modification $(200 \mathrm{mM}$ Tricine for nucleosomal particles and $200 \mathrm{mM}$ Tricine plus $2 \mathrm{M} \mathrm{NaCl}$ for histone octamers). The plot of the amount of histones $\mathrm{H} 2 \mathrm{~A}$ and $\mathrm{H} 2 \mathrm{~B}$ released versus the amount of reagent used or the degree of modification (Figure 4) gives similar curves for the two kinds of particles. The results also indicate that the degree of modification obtained with a certain amount of reagent is approximately the same, within the experimental

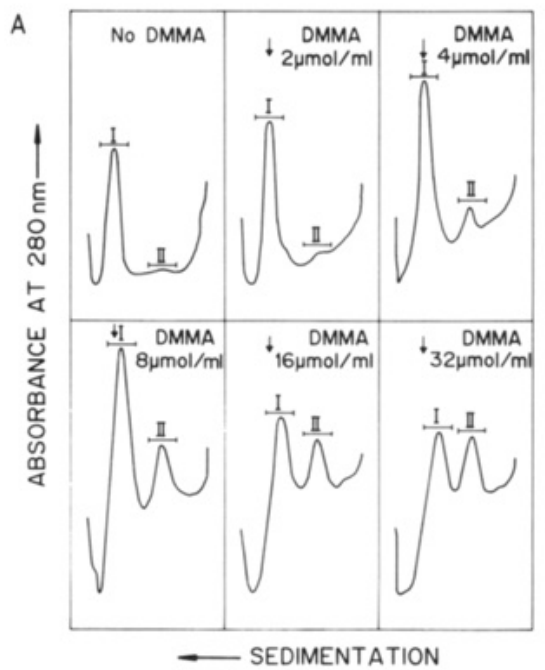

B

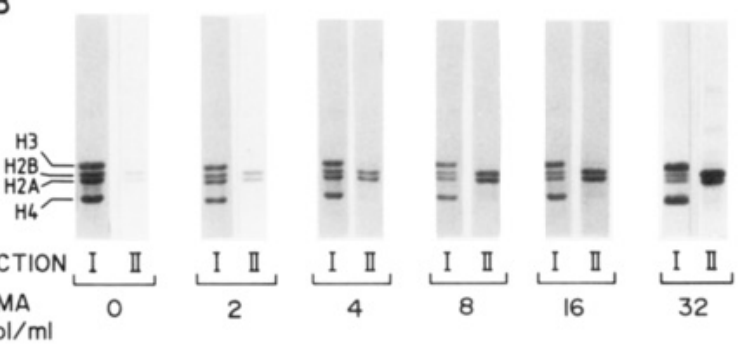

$\mu \mathrm{mol} / \mathrm{ml}$

FIGURE 3: Release from histone octamers of H2A.H2B dimers by modification with DMMA. The preparation of histone octamers was treated, in the presence of $2 \mathrm{M} \mathrm{NaCl}$, with the indicated amounts of DMMA. (A) Sedimentation patterns. The bars (I and II) indicate the fractions isolated for electrophoresis and determination of the extent of histone release (Figure 4). The arrows show the position of the unmodified histone octamers. The increase in the total absorbance of the preparation at $280 \mathrm{~nm}$ with the amount of reagent employed is due to the contribution of the reagent moieties of the modified amino groups, while the elevation of the base line close to the meniscus is produced by the partial regeneration of the modified groups and release of dimethylmaleic acid during centrifugation. (B) Electrophoresis of the histones present in the fractions isolated by centrifugation. The amounts of fractions I and II used for electrophoresis were not complementary.

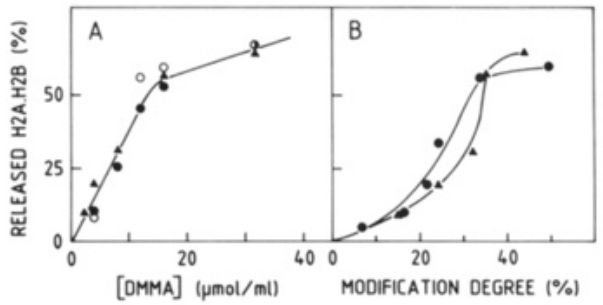

FIGURE 4: Biphasic release of H2A.H2B dimers from nucleosomal particles $(\bullet, O)$ and from the isolated histone octamers $(\boldsymbol{\Lambda})$ by modification with DMMA. (A) The amount of histones H2A and $\mathrm{H} 2 \mathrm{~B}$ released from the particles was determined by measuring the protein content of the fractions isolated by centrifugation (Figures 2 and 3), according to the method of Bradford (1976) (nucleosomal particles, $\bullet$ ) or Lowry et al. (1951) (histone octamers, $\mathbf{\Delta}$ ). With nucleosomal particles, the extent of release of $\mathrm{H} 2 \mathrm{~A}$ and $\mathrm{H} 2 \mathrm{~B}$ was also determined by densitometric analysis of fractions I in the gel shown in Figure 2B (O). (B) The data for histone octamers $(\mathbf{\Delta})$ correspond to the experiment of Figure 3, while those for nucleosomal particles (-) were obtained in an experiment similar to that shown in Figure 2. The modification degree was determined colorimetrically with trinitrobenzenesulfonic acid, for histone octamers, and by measuring radioactivity incorporated, for nucleosomal particles, as described under Materials and Methods.

range studied, for nucleosomal particles and histone octamers. The biphasic release of histones $\mathrm{H} 2 \mathrm{~A}$ and $\mathrm{H} 2 \mathrm{~B}$ found in both cases, with the first phase ending after release of approximately 


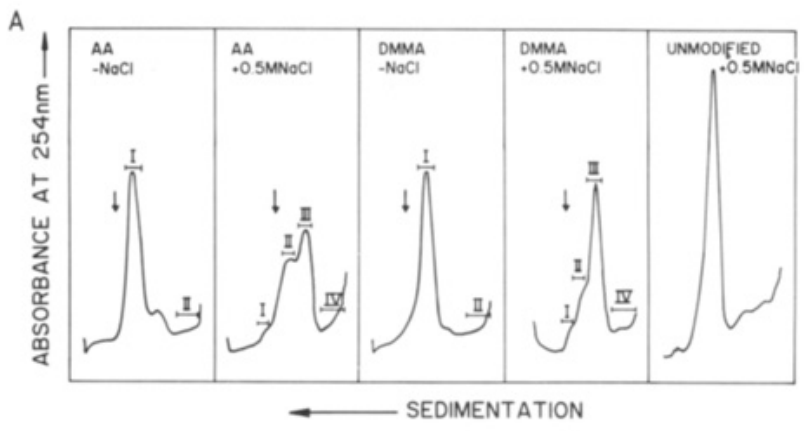

$$
\text { B }
$$
AA

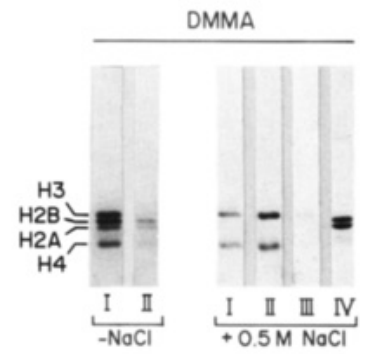

FRACTION $\frac{\text { I } \quad \mathbb{I}}{-\mathrm{NoCl}}$ $\frac{2 \text { II II IV }}{+0.5 \mathrm{M} \mathrm{NoCl}}$

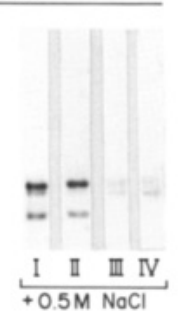

FIGURE 5: Effect of salt $(\mathrm{NaCl})$ on nucleosomal particles modified by AA and DMMA. Nucleosomal particles were treated, in the absence of $\mathrm{NaCl}$, with AA $(10 \mu \mathrm{mol} / \mathrm{mL})$ or DMMA $(8 \mu \mathrm{mol} / \mathrm{mL})$. After modification, the preparations were dialyzed and centrifuged in the absence or presence of $0.5 \mathrm{M} \mathrm{NaCl}$. (A) Sedimentation patterns. The bars (I-IV) indicate the fractions isolated for electrophoresis. The arrows show the position of the corresponding unmodified particles, which were dialyzed and centrifuged under the same conditions as those of the modified particles. (B) Electrophoresis of the histones present in the different fractions isolated by centrifugation.

$50 \%$ of histones $\mathrm{H} 2 \mathrm{~A}$ and $\mathrm{H} 2 \mathrm{~B}$, for a modification of $35 \%$ of the amino groups of histones, and the equimolecular proportion in which both histones are liberated (Figures 2 and 3) are consistent with an asymmetric release of the two $\mathrm{H} 2 \mathrm{~A} \cdot \mathrm{H} 2 \mathrm{~B}$ dimers.

In contrast with the results obtained with DMMA, modification of nucleosomal particles (see below) or core-histone octamers (not shown) with AA is not accompanied by liberation of histones $\mathrm{H} 2 \mathrm{~A}$ and $\mathrm{H} 2 \mathrm{~B}$.

Effect of Salt $(\mathrm{NaCl})$ on the Disassembly of Nucleosomal Particles Modified with AA and DMMA. The effect of salt $(\mathrm{NaCl})$ on the disassembly of nucleosomal particles has been studied in two different ways. The nucleosomal particles modified in the absence of salt were treated with different salt concentrations, or the nucleosomal particles were modified in the presence of salt and the salt was eliminated prior to characterization of the modified preparations.

Figure 5 shows the effect of $0.5 \mathrm{M} \mathrm{NaCl}$ on nucleosomal preparations previously modified with AA or DMMA in the absence of salt. Without salt addition, only the preparation modified with AA has a small amount of free double-stranded DNA. However, after incubation with $0.5 \mathrm{M} \mathrm{NaCl}$, most of the DNA in both modified preparations is found as free DNA (Figure 5A, component III), and two nucleoprotein components can be distinguished in the sedimentation patterns (Figure 5A, components I and II in the salt-treated preparations). Incubation of unmodified nucleosomal particles in 0.5 $\mathrm{M} \mathrm{NaCl}$ produces liberation of only a small amount of free DNA (Figure 5A). Salt treatment of the DMMA-modified preparation causes complete release of histones $\mathrm{H} 2 \mathrm{~A}$ and $\mathrm{H} 2 \mathrm{~B}$, while the two nucleoprotein particles, which lack $\mathrm{H} 2 \mathrm{~A}$ and $\mathrm{H} 2 \mathrm{~B}$, retain all the $\mathrm{H} 3$ and $\mathrm{H} 4$ present in the preparation (Figure 5B).

When modification takes place in the presence of salt and this is eliminated immediately afterward, the results shown in Figure 6 are obtained. The sedimentation patterns of the
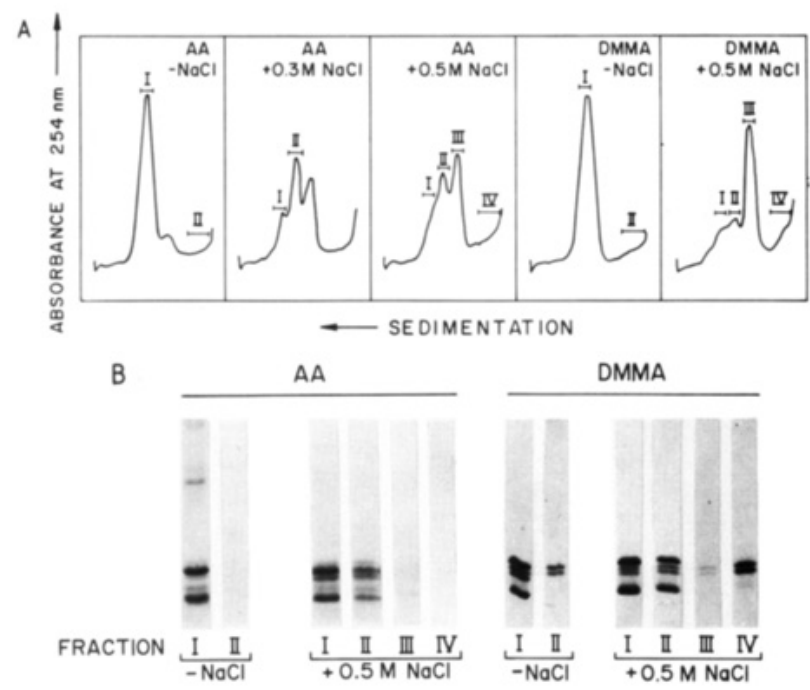

FIGURE 6: Effect of salt $(\mathrm{NaCl})$ during modification of nucleosomal particles with AA and DMMA. Nucleosomal particles were treated with AA $(10 \mu \mathrm{mol} / \mathrm{mL})$ or DMMA $(8 \mu \mathrm{mol} / \mathrm{mL})$, in the absence or in the presence of the indicated concentrations of $\mathrm{NaCl}$. After modification, the preparations were dialyzed and centrifuged in the absence of $\mathrm{NaCl}$. (A) Sedimentation patterns. The bars (I-IV) indicate the fractions isolated for electrophoresis. (B) Electrophoresis of the histones present in the different fractions isolated by centrifugation.

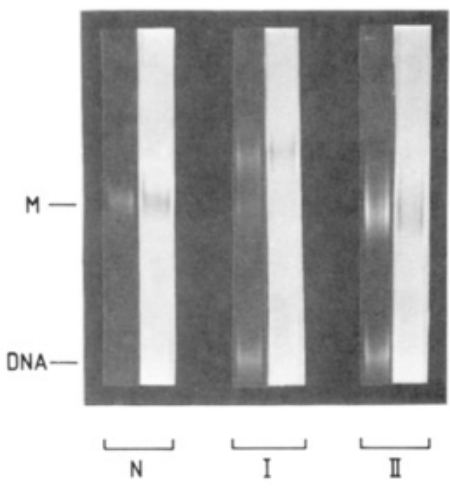

FIGURE 7: Nondenaturant electrophoresis of the two different residual particles obtained by modification of nucleosomal particles with AA in the presence of salt. The samples used were control unmodified nucleosomal particles $(\mathrm{N})$ and the two fractions separated by centrifugation from a preparation modified with AA $(10 \mu \mathrm{mol} / \mathrm{mL})$ in the presence of $0.3 \mathrm{M} \mathrm{NaCl}$ (Figure 6A). For each sample, the electrophoresis strip was stained with ethidium bromide (left) and with Coomassie blue (right). The positions of mononucleosomal particles (M) and of nucleosomal-sized DNA (DNA) are shown.

modified preparations are qualitatively similar to those corresponding to preparations modified in the absence of salt and subsequently incubated with salt (Figure 5). However, in this case, the nucleoprotein components in the preparation modified with DMMA in the presence of $0.5 \mathrm{M} \mathrm{NaCl}$ are not completely devoid of histones H2A and H2B. Electrophoresis under nondenaturing conditions of the nucleoprotein components present in the preparation modified with $\mathrm{AA}$ in the presence of $0.3 \mathrm{M} \mathrm{NaCl}$ (Figure 7) shows that fraction II moves as a single component in the position corresponding to untreated mononucleosomal particles, while fraction I gives two well-separated bands. Fraction II and the fast-moving band from fraction I seem to correspond to nucleosomal particles containing one complement of histones and the slow-moving band in fraction I to nucleoprotein particies with two core-histone octamers.

Disassembly of nucleosomal particles with release of free DNA takes place to a low extent in the absence of $\mathrm{NaCl}$ (in 


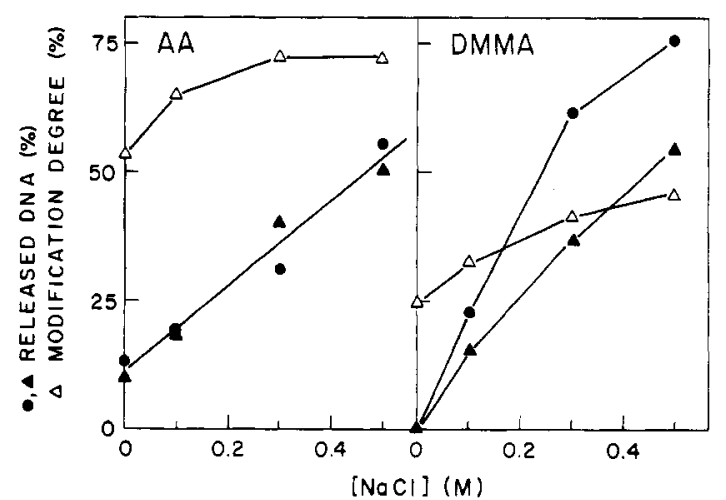

FIGURE 8: Dependence of the amount of DNA released from nucleosomal particles on the salt $(\mathrm{NaCl})$ concentration present during or after modification. Nucleosomal particles were treated with AA $(10 \mu \mathrm{mol} / \mathrm{mL})$ or DMMA $(8 \mu \mathrm{mol} / \mathrm{mL})$. Modification was conducted in the absence of salt $(\mathrm{NaCl})$, and the modified preparation was subsequently dialyzed and centrifuged in the presence of the indicated $\mathrm{NaCl}$ concentrations (๑), or modification was performed in the presence of the indicated concentrations of $\mathrm{NaCl}$ and the subsequent dialysis and centrifugation in the absence of $\mathrm{NaCl}(\boldsymbol{\Lambda})$. In the first case, the degree of modification of the amino groups of histones was $53 \%$ for AA and $25 \%$ for DMMA, while in the second case, it changed with the salt concentration present during modification, the different values being indicated in the figure $(\Delta)$.

$200 \mathrm{mM}$ Tricine). However, the extent of release of free DNA is notably increased by the presence of salt, either during or after modification. Figure 8 shows the results obtained under both experimental conditions. For the preparations modified with AA $(10 \mu \mathrm{mol} / \mathrm{mL})$, the liberation of DNA is approximately the same whether $\mathrm{NaCl}$ is present during or after modification. In contrast, with DMMA the extent of DNA release is larger when salt is present after modification. These results indicate that the dissociation of the modified nucleosomal particles by salt is partially reversible on removal of salt for the particles modified by DMMA but not for those obtained with AA. For the preparations modified with AA, 12\% of the DNA is released in the absence of salt, while no free DNA is found in the DMMA-modified preparations, which is probably due to the much lower modification degree of the preparations modified with DMMA (25\% compared with $53 \%$ for the AA-modified preparations). However, for larger amounts of reagent, liberation by DMMA of free DNA is also obtained in the absence of salt (see Figure 2A).

\section{Discussion}

The observed biphasic release of equimolecular amounts of histones H2A and H2B from nucleosomal particles and from the isolated core-histone octamers, by modification with DMMA, is consistent with the asymmetric dissociation from the particles of the two H2A.H2B dimers. The response to DMMA treatment is similar for the two kinds of particles. Both the modification degree and the amount of $\mathrm{H} 2 \mathrm{~A}$ and H2B liberated for a certain DMMA treatment are similar for the two particles, in spite of the very different ionic conditions used during modification ( $200 \mathrm{mM}$ Tricine, for nucleosomal particles, and $200 \mathrm{mM}$ Tricine plus $2 \mathrm{M} \mathrm{NaCl}$, for histone octamers). These results are in agreement with the proposed structural similarity of the free histone octamer in $2 \mathrm{M} \mathrm{NaCl}$ and the histone octamer associated to DNA in the nucleosomal particle (Thomas \& Kornberg, 1975; Uberbacher et al., 1986). Apparently, the weakening of the electrostatic repulsion forces brought about by high ionic strength is structurally equivalent to the neutralization of the positive charges of histones by interaction with DNA.

The results reported in a previous work (Jordano et al.,
1985 ) indicate that the asymmetric dissociation of $\mathrm{H} 2 \mathrm{~A} \cdot \mathrm{H} 2 \mathrm{~B}$ dimers induced by DMMA modification is consistent with equivalent binding sites in the nucleosomal particles for the two $\mathrm{H} 2 \mathrm{~A} \cdot \mathrm{H} 2 \mathrm{~B}$ dimers rather than with intrinsically different sites. The negative cooperativitiy in the dissociation of the $\mathrm{H} 2 \mathrm{~A} \cdot \mathrm{H} 2 \mathrm{~B}$ dimers might be related to the structural dynamics of nucleosomes in vivo. Baer and Rhodes (1983) found that the nucleosomal particles that bind to RNA polymerase II in vitro are enriched in transcribed DNA sequences and are deficient in histones $\mathrm{H} 2 \mathrm{~A}$ and $\mathrm{H} 2 \mathrm{~B}$. They proposed that the nucleosomal particles present in transcriptionally active chromatin may be deficient in $\mathrm{H} 2 \mathrm{~A}$ and $\mathrm{H} 2 \mathrm{~B}$ in the cell. Recent work from our laboratory (Gonzälez et al., 1987) shows that core particles lacking one $\mathrm{H} 2 \mathrm{~A} \cdot \mathrm{H} 2 \mathrm{~B}$ dimer interact with RNA polymerase from Escherichia coli more strongly than whole core particles, being also more efficient as transcription templates. A negative cooperativity in the dissociation of the two H2A.H2B dimers from nucleosomal particles would facilitate the formation of particles containing only one $\mathrm{H} 2 \mathrm{~A} \cdot \mathrm{H} 2 \mathrm{~B}$ dimer. The finding that, in the cell, newly synthesized $\mathrm{H} 2 \mathrm{~A}$ and $\mathrm{H} 2 \mathrm{~B}$ are incorporated as $\mathrm{H} 2 \mathrm{~A} \cdot \mathrm{H} 2 \mathrm{~B}$ dimers into nucleosomal particles containing one old $(\mathrm{H} 3 \cdot \mathrm{H} 4)_{2}$ tetramer and one old H2A.H2B dimer (Jackson, 1987) suggests that nucleosomal particles deficient in one $\mathrm{H} 2 \mathrm{~A} \cdot \mathrm{H} 2 \mathrm{~B}$ dimer are important structural intermediates in chromatin dynamics.

The liberation of H2A.H2B dimers from nucleosomal particles and free core-histone octamers described in this paper allows the preparation of nucleosomal particles lacking one $\mathrm{H} 2 \mathrm{~A} \cdot \mathrm{H} 2 \mathrm{~B}$ dimer and of core-histone hexamers formed by one $(\mathrm{H} 3 \cdot \mathrm{H} 4)_{2}$ tetramer and one $\mathrm{H} 2 \mathrm{~A} \cdot \mathrm{H} 2 \mathrm{~B}$ dimer. Under the modification conditions employed in the present work, release of $50 \%$ of the $\mathrm{H} 2 \mathrm{~A}$ and $\mathrm{H} 2 \mathrm{~B}$ from a preparation of nucleosomal particles can be obtained without liberation of free DNA, thus avoiding the formation of particles containing extra histones, which takes place when there is liberation of free DNA by the presence of salt (this work) or by addition of base to prevent the fall in $\mathrm{pH}$ during modification (Jordano et al., 1984a, 1985).

The liberation of free double-stranded DNA by modification of nucleosomal particles with AA, at salt concentrations much lower than those needed to dissociate untreated nucleosomes (Figure 8), supports the involvement of lysine residues in the binding of histones to DNA in the nucleosomal particle. A similar release of DNA upon modification with AA is also found with trypsin-digested core particles (unpublished results).

Salt concentrations lower than $0.5 \mathrm{M} \mathrm{NaCl}$, which are unable to dissociate native nucleosomal particles, cause the release of free DNA from nucleosomal particles modified with AA or DMMA. In the modified particles, the electrostatic interactions between histones and DNA are already weakened by the modification of lysine residues. Therefore, a small additional effect of ionic strength is sufficient to dissociate DNA from histones.

When modification of nucleosomal particles takes place under conditions that cause liberation of free double-stranded DNA, the histones corresponding to the released DNA bind as extra histones to the residual DNA-containing particles. These results are in agreement with the reported binding of additional molecules of $\mathrm{H} 3$ and $\mathrm{H} 4$ or core-histone octamers to the surface of nucleosomal cores (Klevan et al., 1978; Voordouw \& Eisenberg, 1978; Stein, 1979; Eisenberg \& Felsenfeld, 1981). With AA, which causes no dissociation of the core-histone octamer, complete histone octamers would bind to the undissociated nucleosomal particles, while, with DMMA, which causes liberation of $\mathrm{H} 2 \mathrm{~A} \cdot \mathrm{H} 2 \mathrm{~B}$ dimers, 
$(\mathrm{H} 3 \cdot \mathrm{H} 4)_{2} \mathrm{H} 2 \mathrm{~A} \cdot \mathrm{H} 2 \mathrm{~B}$ hexamers and $(\mathrm{H} 3 \cdot \mathrm{H} 4)_{2}$ tetramers would also bind as extra histones, the relative amounts of the three particles depending on the degree of modification and the salt concentration.

\section{ACKNOWLEDGMENTS}

We thank Santiago de la Escalera for his valuable help in performing the experiment shown in Figure 2. Chicken blood was kindly donated by AVESUR (Madrid).

\section{REFERENCES}

Baer, B. W., \& Rhodes, D. (1983) Nature (London) 301, 482-488.

Bernad, A., Nieto, M. A., Vioque, A., \& Palaciăn, E. (1986) Biochim. Biophys. Acta 873, 350-355.

Bradford, M. M. (1976) Anal. Biochem. 72, 248-254.

Eisenberg, H. \& Felsenfeld, G. (1981) J. Mol. Biol. 150, 537-555.

González, P. J., Martínez, C., \& Palaciån, E. (1987) J. Biol. Chem. 262, 11280-11283.

Jackson, V. (1987) Biochemistry 26, 231 5-2325.

Jordano, J., Montero, F., \& Palaciân, E. (1984a) Biochemistry 23, 4280-4284.

Jordano, J., Montero, F., \& Palaciån, E. (1984b) Biochemistry 23, 4285-4289.

Jordano, J., Montero, F., \& Palaciăn, E. (1984c) Biochem. Biophys. Res. Commun, 121, 907-914.
Jordano, J., Nieto, M. A., \& Palaciăn, E. (1985) J. Biol. Chem. 260, 9382-9384.

Klevan, L., Dattagupta, N., Hogan, M., \& Crothers, D. M. (1978) Biochemistry 17, 4533-4540.

Lacy, E., \& Axel, R. (1975) Proc. Natl. Acad. Sci. U.S.A. 72, 3978-3982.

Laemmli, U. K. (1970) Nature (London) 227, 680-685.

Lowry, O. H., Rosebrough, N. J., Farr, A. L., \& Randall, R. J. (1951) J. Biol. Chem. 193, 265-275.

Nieto, M. A., \& Palaciản, E. (1987) Biochem. J. 241, 621-623.

Reeves, R. (1984) Biochim. Biophys. Acta 782, 343-393.

Ruiz-Carrillo, A., \& Jorcano, J. L. (1979) Biochemistry 18, 760-768.

Stein, A. (1979) J. Mol. Biol. 130, 103-134.

Thomas, J. O., \& Kornberg, R. D. (1975) Proc. Natl. Acad. Sci, U.S.A. 72, 2626-2630.

Uberbacher, E. C., Harp, J. M., Wilkinson-Singley, E., \& Bunick, G. J. (1986) Science (Washington D.C.) 232, 1247-1249.

Voordouw, G., \& Eisenberg, H. (1978) Nature (London) 273, 446-448.

Weintraub, H., Palter, K., \& Van Lente, F. (1975) Cell (Cambridge, Mass.) 6, 85-110.

Weisbrod, S. (1982) Nature (London) 297, 289-295.

Wong, T. K., \& Marushige, K. (1976) Biochemistry 15, 2041-2046.

\title{
Synthesis of a Biological Active Turior Growth Factor from the Predicted DNA Sequence of Shope Fibroma Virus ${ }^{\dagger}$
}

\author{
Yao-Zhong Lin, Gregg Caporaso, Pi-Yun Chang, Xiao-Hong Ke, and James P. Tam* \\ The Rockefeller University, 1230 York Avenue, New York, New York 10021-6399 \\ Received November 10, 1987; Revised Manuscript Received March 22, 1988
}

\begin{abstract}
A 55-residue peptide comprising the carboxyl portion (residues 26-80) of the Shope fibroma virus growth factor (SFGF), a predicted 80-residue DNA virus gene product that encoded a homologous sequence with the epidermal growth factor transforming growth factor $\alpha$ family, was synthesized by a stepwise solid-phase method. The synthetic SFGF (26-80) purified to homogeneity by reverse-phase HPLC was characterized by fission ionization mass spectrometry and amino acid analysis. The disulfide pairings were established by enzymatic digestion and mass spectrometry and were found to be similar to those of EGF and TGF $\alpha$. Synthetic SFGF (26-80) was found to share about $10 \%$ of the activities as EGF in the radioreceptor binding to $A 431$ cells, stimulation of $\left[{ }^{3} \mathrm{H}\right]$ thymidine uptake in NRK cells, and induction of colony formation in soft-agar assay. Our results therefore confirmed that SFGF contained the putative biological activities of the EGF-TGF $\alpha$ family and that production of SFGF by Shope fibroma virus infected cells may account for the proliferative diseases associated with this particular virus.
\end{abstract}

$\mathbf{P}$ comprises a large group of eukaryotic DNA virus whose exceptionally large double-stranded DNA genomes replicate within virosomes in the cytoplasm of the infected host cells. Several poxviruses are known to be responsible for proliferative tumorigenic diseases. Three notable examples of tumorigenic poxviruses are the following: (1) Shope fibroma virus (SFV)' ${ }^{1}$ (Shope, 1932; Chang et al., 1987), which induces

\footnotetext{
${ }^{\dagger}$ This work was supported by USPHS Grant CA 36544 , awarded by the National Cancer Institute, DHHA.

* To whom correspondence should be addressed.
}

benign fibromas in adult rabbit; (2) Yaba tumor virus, which causes subcutaneous histiocytomas in monkeys and man (Bearcroft \& Jamieson, 1958); and (3) Molluscum contagiosum, which produces tumor-like epidermal lesions in man

\footnotetext{
${ }^{1}$ Abbreviations: Boc, tert-butoxycarbonyl; DCC, dicyclohexylcarbodiimide; DIEA, diisopropylethylamine; DMS, dimethyl sulfide; EGF, epidermal growth factor; HPLC, high-performance liquid chromatography; SFGF, Shope fibroma virus growth factor; SFV, Shope fibroma virus; TFA, trifluoroacetic acid; TGF $\alpha$, transforming growth factor $\alpha$; $\mathrm{VGF}$, vaccinia virus growth factor.
} 